\title{
Conservative management of mandibular fracture with maxillomandibular fixation using orthodontic brackets and elastics:
} A case report

Alina Rai ${ }^{1}$, (1) Mamta Dali ${ }^{2}$, (1) Sneha Shrestha ${ }^{3}$, (1) Pradeep Acharya ${ }^{4}$

\section{Highlights}

This case report enlightens the novel closed fracture reduction technique of mandibular fracture management with maxillomandibular fixation using orthodontic brackets and elastics.
Conservative management is the mainstay management of fracture in children. Orthodontic brackets and elastics are non-invasive and cost effective.
This method shows a promising result and can be used in some selective cases.
${ }^{1}$ Junior resident, Department of Pedodontics and Preventive Dentistry,

B.P Koirala Institute of Health Science,

Dharan, Nepal.

2 Associate Professor, Department of Pedodontics and Preventive Dentistry,

B.P Koirala Institute of Health Science,

Dharan, Nepal

3 Assistant Professor, Department of

Pedodontics and Preventive Dentistry,

B.P Koirala Institute of Health Science,

Dharan, Nepal

4 Associate Professor, Department of Oral and Maxillofacial Surgery,

B.P Koirala Institute of Health Science,

Dharan, Nepal

\section{Correspondence:}

B.P Koirala Institute of Health Science,

Dharan, Nepal.

E-mail address:

alinapr.rg@gmail.com

\section{Abstract}

Mandibular fracture is the most common facial skeletal injury in pediatric population seen in hospital setting. Fracture management is complicated by the developing permanent tooth buds and continuous mandibular growth. However, healing capacity in children is faster. Hence, conservative management is most often the treatment of choice for bone fractures in children. This case report is about a 6-year-old female child who sustained mandibular fracture after a road traffic accident (RTA) which was conservatively managed with maxillomandibular fixation using brackets and elastics. Orthodontic brackets were placed on facial aspect of posterior teeth of both the arches and elastics were used for traction leading to immobilization and stabilization of fracture. Healing was uneventful with complete bony union as evident by three months follow up orthopantomogram. Maxillomandibular fixation using brackets and elastics is a simple and noninvasive closed fracture reduction technique giving excellent result. The present case report showed successful outcome of mandibular fracture management.

Keywords: Closed Fracture Reduction; Maxillomandibular Fixation; Mandibular Fractures 


\section{INTRODUCTION}

Mandible is largest, strongest facial bone and also the most commonly involved bone in pediatric facial fractures seen in hospital setting. ${ }^{1}$ Most common sites of mandibular fracture are condyle followed by angle, symphysis and body ${ }^{2}$ with the main cause being road traffic accidents (RTA). ${ }^{3}$

Mandibular fracture should be managed early since delay in treatment can result in facial asymmetry, malocclusion and temporomandibular dysfunction. ${ }^{4}$ Treatment option varies from that of adult. ${ }^{5}$ Minimally invasive procedures are adopted in pediatric mandibular fracture to avoid post operative functional or growth related complications. ${ }^{6}$ Various available options for moderately displaced fracture include closed fracture reduction by maxillomandibular fixation with eyelet wiring and arch bars, acrylic splinting, ${ }^{7}$ orthodontic vacuum-formed thermoplastic splint, ${ }^{8}$ orthodontic brackets and elastics. ${ }^{9}$ Open reduction internal fixation is recommended for severely displaced fracture. ${ }^{10}$
This case report is about the conservative management of mandibular fracture in a child with maxillomandibular fixation using orthodontic brackets and elastics which can be utilized for such cases in future.

\section{CASE REPORT}

A 6-year-old female child patient accompanied by her parents visited the Department of Pedodontics and Preventive Dentistry 24 hours following road traffic accident. Patient was well oriented. Medical or dental history was not significant. Procedure was explained to the parents and written consent was obtained for the treatment and publication of the case report.

Extra oral examination revealed diffuse swelling and tenderness in the right mandibular body region. Mouth opening was adequate with intact temporomandibular joint. Intraoral examination revealed gingival inflammation distal to 85 . The occlusion was within normal limit.

Orthopantomogram (OPG) revealed fracture of right body of mandible with displacement (Figure 1). According to the Dingman and Natvig classification, ${ }^{11}$ it was diagnosed as unfavorable fracture of the right body of the mandible.

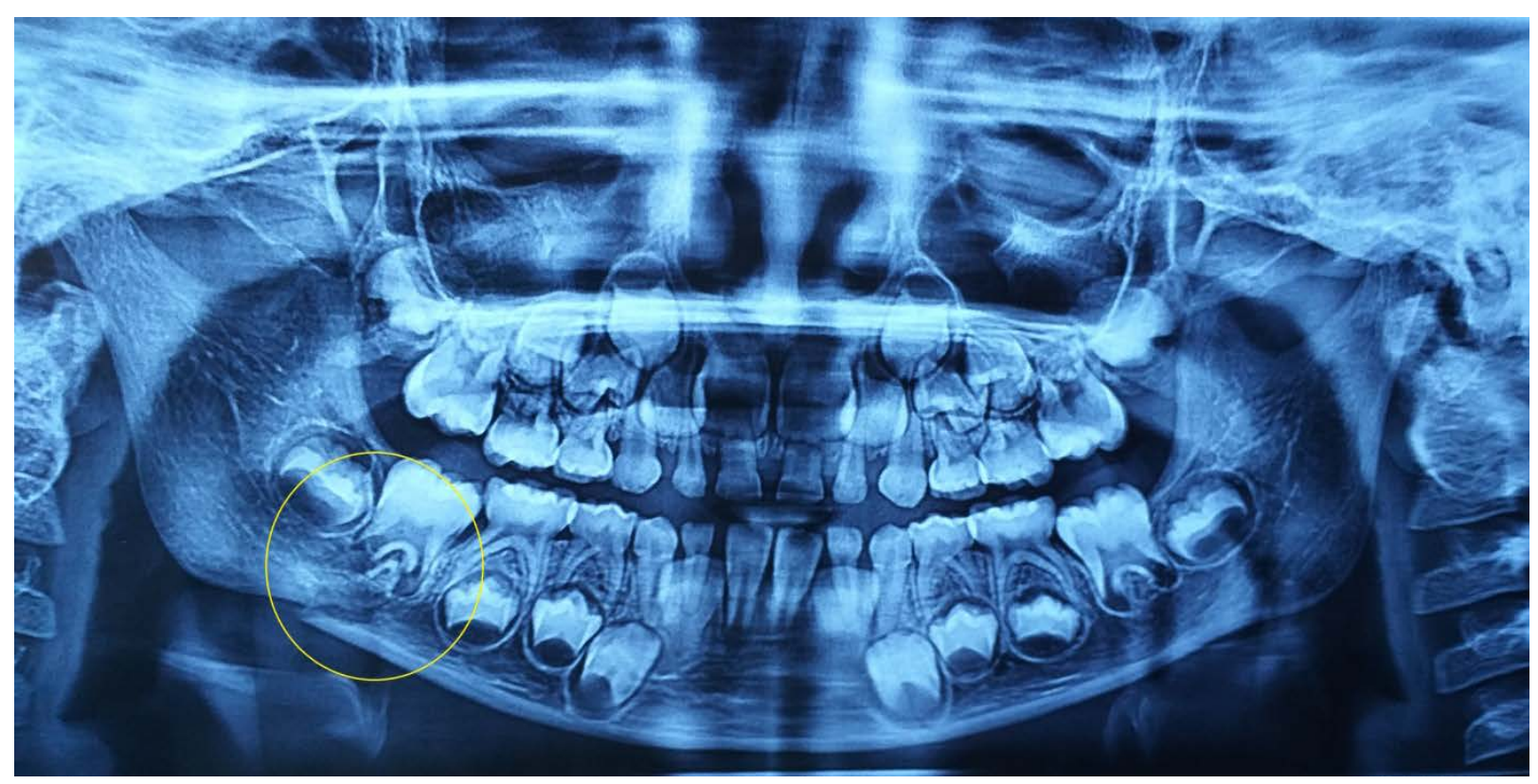

Figure 1. Fracture of the right body of mandible with displacement 
Closed fracture reduction by maxillomandibular fixation using orthodontic brackets and elastics was planned. Stainless steel orthodontic brackets with hooks were bonded using composite on the facial surfaces of 53545563646573747583 84 and $1 / 4$ " blue color elastics were placed from the upper hook to the lower hook in figure of 8 (Figure 2) under local anesthesia. Finally, the occlusion was verified.

Patient was discharged with antibiotics, analgesics and chlorhexidine mouthwash. Patient had already received a dose of tetanus toxoid injection in the emergency. Patient's parents were advised to change the elastics every day and to provide only liquid diet. She was instructed to limit the mandibular movements and also the outdoor activities.

On recall visit after a week, extra oral swelling had significantly subsided and the intraoral healing was uneventful. Two brackets from 84 and 75 had debonded which was rebonded using composite. On the fourth week, the brackets were debonded (Figure 3). There was no pain or swelling. On three months follow up, intra oral examination revealed erupting 46 and OPG showed complete bony union (Figure 4).

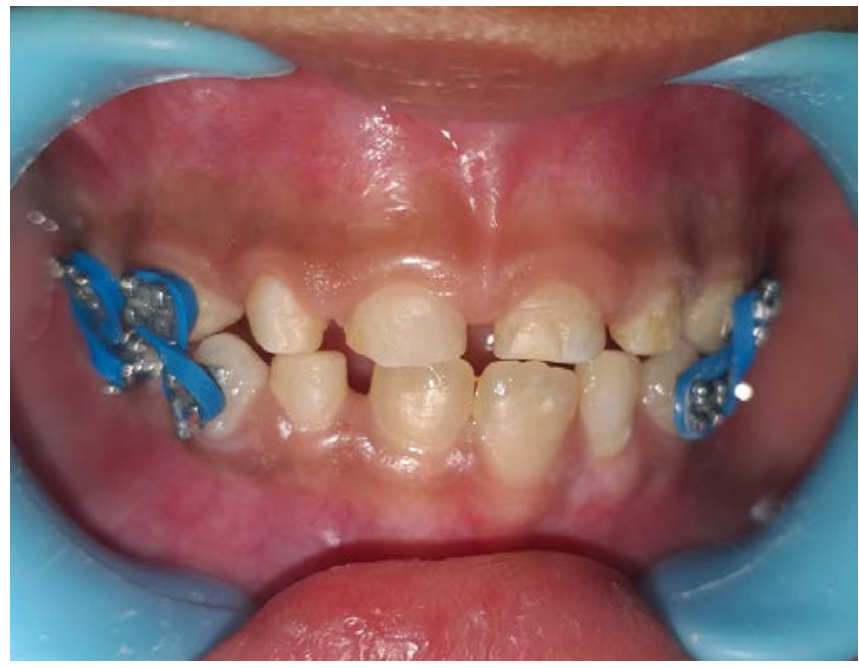

Figure 2. Maxillomandibular fixation with brackets and elastics

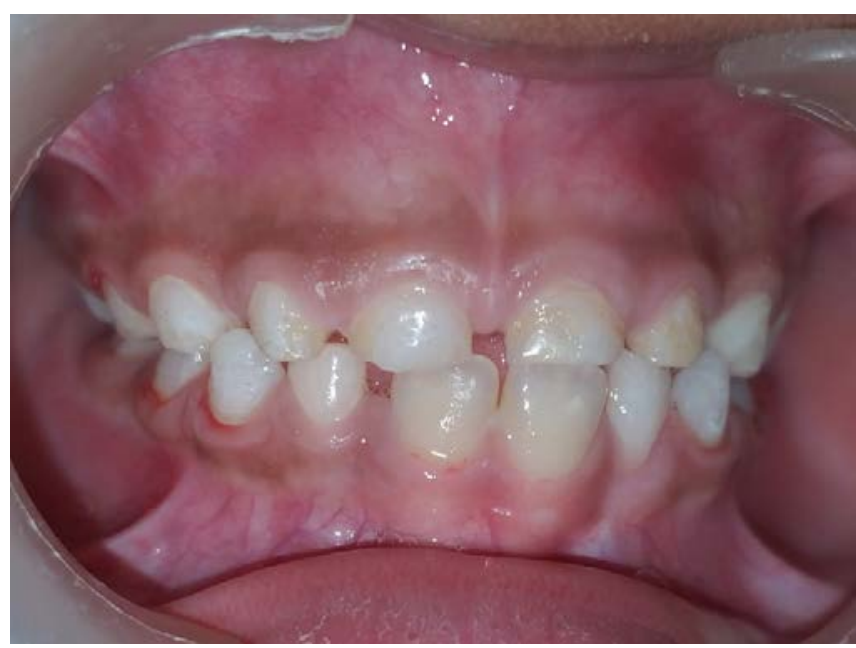

Figure 3. After debonding of brackets

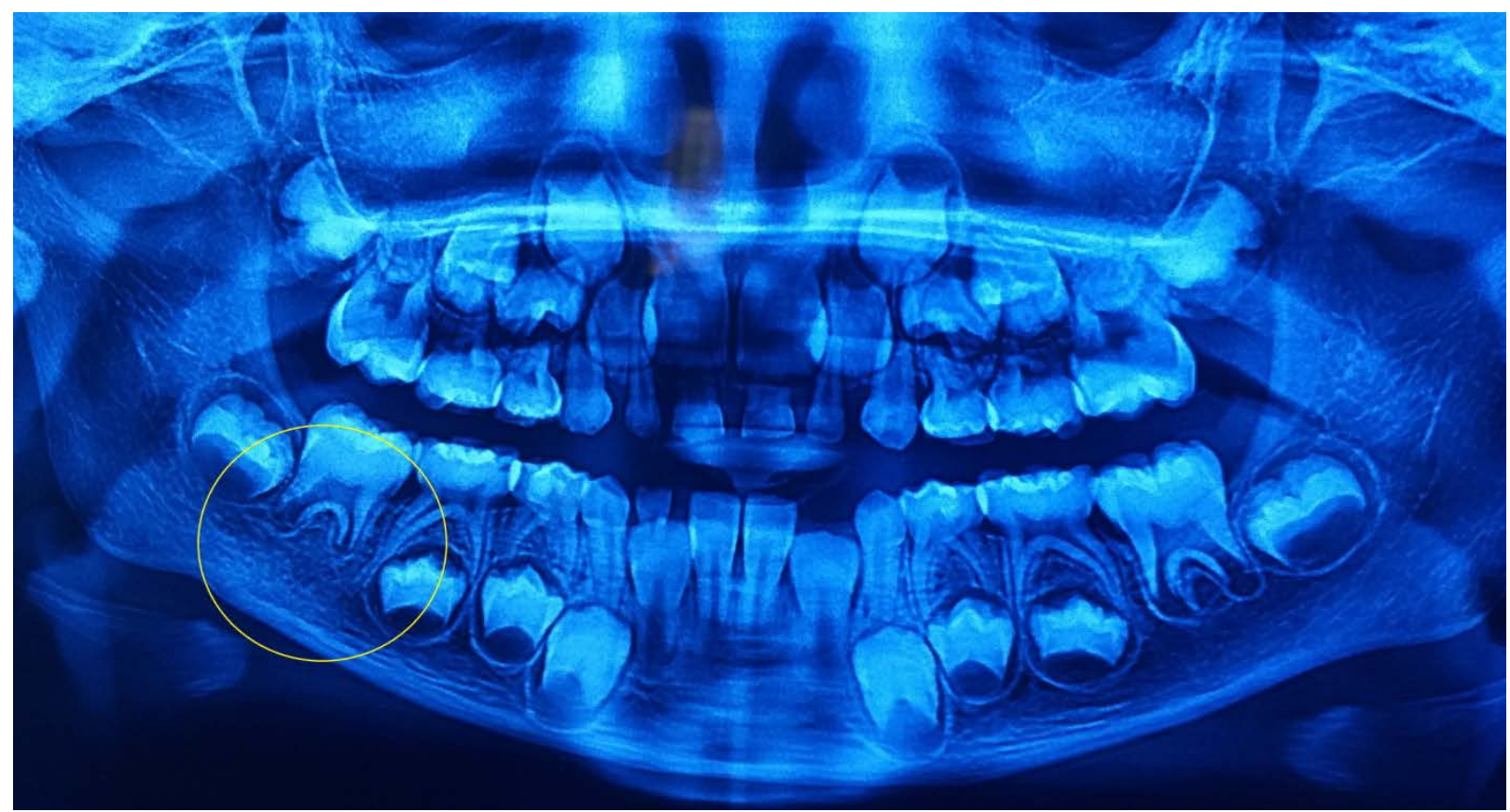

Figure 4. Healing of fracture with proper alignment 


\section{DISCUSSION}

More than $50 \%$ of the pediatric facial fractures are seen in the mandible and their management depends upon the dental age as well as the type of fracture. ${ }^{12}$ In case of children, minimal manipulation of jaw is required. Children have higher bone remodeling potential and rapid healing rate. Hence early management with shorter immobilization period than adults (2-3 weeks vs 4-6 weeks in adult) result in excellent healing. ${ }^{10}$

In case of greenstick fracture or non displaced fracture, conservative management is suggested. Close observation, soft diet and analgesics will suffice. In case of displaced fracture, close or open reduction with fixation is indicated. In case of moderately displaced fracture, closed fracture reduction technique is the ideal treatment. This technique involves acrylic splints with circummandibular wiring, maxillomandibular fixation with arch bars and eyelet wiring and vacuum formed thermoplastic splint. Open reduction is indicated in older children and with severely displaced fractures or fracture of angle of mandible. ${ }^{10}$

In this case, since fracture was distal to the last clinical tooth i.e. right second deciduous molar, acrylic splint or thermoplastic splint was not used. Maxillomandibular fixation using arch bars and wire was also avoided since primary teeth are not stable and can avulse on excessive force. ${ }^{13}$ The option of open reduction and internal fixation was discarded due to the presence of permanent tooth buds. Thus conservative management with closed fracture reduction was planned using orthodontic brackets and elastics. Orthodontic brackets were used to engage the elastics from upper arch to lower arch which allowed limited mobility of the jaw and stabilization of the fracture. ${ }^{14}$ It was changed daily to maintain adequate traction. Hence there was uneventful healing of the fracture.

Maxillomandibular fixation using brackets and elastics is a novel and non-invasive technique with good prognosis. The advantages of this procedure are: it is cost effective with no special instruments required and no laboratory work. The adverse effects and economical burden of General Anesthesia can be avoided. However, the disadvantages are: difficulty in maintaining oral hygiene, is technique sensitive and weight loss of the patient (due to liquid diet). This procedure is not useful in case of severely displaced fracture. Both parent and patient cooperation and compliance are utmost for the success of treatment. However, literature is scarce ${ }^{15,16}$ supporting this treatment plan, hence more prospective studies are required to advocate for and recommend the procedure.

\section{CONCLUSIONS}

Closed fracture reduction using orthodontic brackets and elastics is an innovative and conservative chair side procedure. After proper case selection, this technique can be used to effectively and efficiently manage moderately displaced fracture in children.

\section{REFERENCES}

1. Vyas RM, Dickinson BP, Wasson KL, Roostaeian J, Bradley JP. Pediatric facial fractures: Current national incidence, distribution, and health care resource use. J Craniofac Surg 2008;19:339-349

2. Mukhopadhyay S. A retrospective study of mandibular fractures in children. J Korean Assoc Oral Maxillofac Surg 2018;44:269-274

3. Lida S, Matsuya T. Paediatric maxillofacial fractures: Their aetiological characters and fracture patterns. J Cranio-Maxillofacial Surg 2002;30:237-241

4. Elgehani RA, Orafi MI. Incidence of mandibular fractures in Eastern part of Libya. Med Oral Patol Oral Cir Bucal 2009;14:529-532

5. Wolfswinkel EM, Weathers WM, Wirthlin JO, Monson LA, Hollier LH, Khechoyan DY. Management of Pediatric Mandible Fractures. Otolaryngol Clin North Am 2013;46:791-806

6. Crean SJ, Sivarajasingam V, Fardy MJ. Conservative approach in the management of mandibular fractures in the early dentition phase. A case report and review of the literature. Int J Paediatr Dent 2000;10:229-233

7. Aboelgheit M. Management of mandibular fracture in pediatric patient: A case report. Asian Pacific J Heal Sci 2017;4:81-83 
8. Sanu OO, Ayodele AOS, Akeredolu MO. Management of pediatric mandibular fracture using orthodontic vacuum-formed thermoplastic splint: A case report and review of literature. Niger J Clin Pract 2017;20:637-641

9. Gawelin PJE, Thor ALI. Conservative treatment of paediatric mandibular fracture by the use of orthodontic appliance and rubber elastics: Report of a case. Dent Traumatol 2005;21:57-59

10. Zimmermann CE, Troulis MJ, Kaban LB. Pediatric facial fractures: Recent advances in prevention, diagnosis and management. Int J Oral Maxillofac Surg 2006;35:2-13

11. Mihailova H. Classifications of Mandibular Fractures - Review. J of IMAB. 2006;12:3-5

12. Gassner R, Tuli T, Hächl $O$, Rudisch A, Ulmer H. Cranio-maxillofacial trauma: A 10 year review of 9543 cases with 21067 injuries. J Cranio-Maxillofacial Surg 2003;31:51-61

13. Aizenbud D, Hazan-Molina H, Emodi O, Rachmiel A. The management of mandibular body fractures in young children. Dent Traumatol 2009;25:565-570

14. Kaya CD, Kaya D, Kocadereli I, Akcan AC, Surgery AR. Use of Acrylic Occlusal Splint and Direct Bonded Brackets for Intermaxillary Fixation in the Treatment of Unilateral Parasymphyseal and Condylar Fractures: a Case Report. Clin Dent Res 2013;37:46-50.

15. Pandey R, Khatri A, Gupta R, Bhagat N. Use of orthodontic brackets for intermaxillary fixation for management of mandibular fracture in a pediatric patient. J Dent Allied Sci 2017;6:35-39

16. Madhusudhan KS. Orthodontic Brackets As Intermaxillary Fixation: A Case Report. J Pediatr Oral Heal Res 2017;1:16-19

\section{How to cite this article:}

Alina Rai, Mamta Dali, Sneha Shrestha, Pradeep Acharya. Conservative management of mandibular fracture with maxillomandibular fixation using orthodontic brackets and elastics: A case report. Contemp Pediatr Dent 2020:1(1):5256.

\section{Declarations}

Acknowledgements: Not applicable.

Conflict of Interest Statement: The authors disclose no potential conflicts of interest.

Ethics Statement: Procedure was explained to the parents and written consent was obtained for the treatment and publication of the case report.

Informed Consent: Written consent was taken for participation of both parents and children in the study.

Author contributions: Conception and design: All Authors; Acquisition of data: AR; Interpretation of data: AR; Drafting article: $A R, M D$; Revision artice: $S S, P A$; Final approval: All Authors

Funding: This work is not finantiated.

Data Availability: The data used to support the findings of this study can be made available upon request to the corresponding author.

Peer-review: Externally double-blinded peer-reviewed. 